\title{
Possible Involvement of Androgen in Increased Norepinephrine Synthesis in Blood Vessels of Spontaneously Hypertensive Rats
}

\author{
Toshio Kumai, Masami Tanaka, Minoru Watanabe, Chie Matsumoto and Shinichi Kobayashi \\ Department of Pharmacology, St. Marianna University School of Medicine, 2-16-1 Sugao, Miyamae-ku, Kawasaki 216, Japan \\ Received April 1, $1994 \quad$ Accepted September 12, 1994
}

\begin{abstract}
We investigated the effects of castration and testosterone propionate on sympathetic nervous systems in spontaneously hypertensive rats (SHR) and Wistar Kyoto rats (WKY). Four-week-old male rats were castrated. For replacement of androgen, testosterone propionate ( $500 \mu \mathrm{g} / \mathrm{rat})$ was administered subcutaneously 2 times a week to castrated rats after their 14th week. The systolic blood pressure of the castrated SHR (44 weeks) was significantly lower than those of intact SHR and testosterone-replaced SHR. The norepinephrine (NE) levels and the tyrosine hydroxylase (TH) activities in the abdominal aorta and mesenteric artery of castrated SHR (45-50 weeks) were significantly lower than those of intact SHR. The $\mathrm{NE}$ levels and the TH activities in these blood vessels of testosterone-replaced SHR recovered to the levels obtained in those of intact SHR. As well as the systolic blood pressure, the NE levels and TH activities in blood vessels of WKY were significantly lower than those of intact SHR and showed no significant difference among the three groups. These results suggest that androgen may contribute to the development of hypertension in SHR via sustained enhancement of TH activity in blood vessels leading to increased NE level.
\end{abstract}

Keywords: Tyrosine hydroxylase, Norepinephrine, Androgen, Blood vessel, Spontaneously hypertensive rat

The sympathetic nervous system is thought to play an important role in pathogenesis of hypertension in spontaneously hypertensive rats (SHR) (1). Many studies suggested that norepinephrine (NE) in the plasma and heart is increased concomitantly with the increased catecholamine synthesizing enzyme activities in blood vessels of SHR (2-4). Judy et al. (5) reported that sympathetic nerve activity is increased in the nerves distributing to the abdominal regions in SHR. Iriuchijima (6) reported that the high vascular resistance in hindquarter and mesenteric arteries of SHR is maintained by an elevated sympathetic tone. Therefore, increased sympathetic tone or sympathetic nerve activity in arteries of these regions may contribute to hypertension in SHR.

There are epidemiological and experimental evidence suggesting that androgen contributes to hypertension (7, $8)$. We have reported that castration retards the development of hypertension in SHR (9). Cambotti et al. (10) demonstrated that neonatally-androgenized female SHR exhibited a pattern of increase in blood pressure similar to that of male SHR during maturation. Furthermore, Ganten et al. (11) demonstrated that chemical castration with cyproterone and flutamide, which are androgen receptor antagonists, attenuated the development of hypertension in male SHR. Thus, androgen appears to be involved in the development and maintenance of hypertension in SHR, but its mechanisms are not yet clear. Recently, Hamill and Schroeder (12) reported that androgen facilitates neuronal activity. Therefore, it is expected that androgen might elevate blood pressure in SHR via potentiation of sympathetic nerve activities.

To evaluate this assumption, in the present study, we investigated the effects of castration and testosterone on $\mathrm{NE}$ level and tyrosine hydroxylase (TH) activity as indices of sympathetic nerve activities in the abdominal aorta and mesenteric artery of SHR.

\section{MATERIALS AND METHODS}

\section{Animals}

Four-week-old male SHR and Wistar Kyoto rats (WKY) were castrated under light ether anesthesia. The rats were housed in a semi-barrier system, in a room where temperature $\left(23 \pm 1{ }^{\circ} \mathrm{C}\right)$, humidity $(55 \pm 5 \%)$ and lighting (06:00-18:00) were controlled. 


\section{Drug treatment}

Testosterone propionate (500 $/ \mathrm{g} / \mathrm{rat}$; Wako, Osaka) dissolved in sesame oil $(500 \mu \mathrm{g} / 0.1 \mathrm{ml})$ was administered subcutaneously 2 times a week to castrated rats between their 14 th week and the week of their sacrifice.

\section{Blood pressure measurement}

Systolic blood pressure was measured by the tail cuff method (Riken Kaihatsu PS-100, Tokyo) in conscious animals placed on a hot plate $\left(37^{\circ} \mathrm{C}\right)$ at the age of 44 weeks. Six to seven blood pressure readings were obtained for each rat, and these were averaged.

\section{Norepinephrine analysis}

Rats were decapitated at the age of $45-50$ weeks ( $24 \mathrm{hr}$ after the final administration of testosterone propionate), and the abdominal aorta and mesenteric arteries were quickly removed. These tissues were defatted and rinsed with cold saline.

The tissues were homogenized in $1.05 \mathrm{ml}$ of ice-cold $0.05 \mathrm{M}$ perchloric acid with $5 \mathrm{ng}$ dihydroxybenzylamine, an internal standard, in a glass tissue grinder. The homogenate was centrifuged at $15,000 \times \mathrm{g}$ for $20 \mathrm{~min}$ at $4{ }^{\circ} \mathrm{C}$ and the supernatant was used for the assay of NE. NE was extracted with aluminum oxide. The supernatant was mixed with $10 \mathrm{mg}$ aluminum oxide and $100 \mu \mathrm{l}$ of $2 \mathrm{M}$ Tris-EDTA (pH 8.7) for $15 \mathrm{~min}$. The precipitate was washed with $1 \mathrm{ml}$ of $16.5 \mathrm{mM}$ Tris-EDTA ( $\mathrm{pH} \mathrm{8.1)}$. The precipitate was then dried and mixed with $200 \mu l$ of solvent medium (acetic acid : 10\% sodium metabisulfite : 5\% EDTA : water $=0.1: 0.05: 0.05: 9.8$ ) for $15 \mathrm{~min}$, followed by centrifugation at $1,800 \times g$ for $1 \mathrm{~min}$. The supernatant was passed through a $0.22-\mu \mathrm{m}$ filter, and a $10-\mu 1$ aliquot was injected into the HPLC (Waters, Milford, MA USA, 510) instrument, which was equipped with an electrochemical detector (Waters 460) and a Cosmosil $5 \mathrm{C}_{18}$-AR packed column $(4.6 \times 150 \mathrm{~mm}$; Nacalai Tesque Co., Kyoto). The mobile phase consisted of the following components: $50 \mathrm{mM}$ sodium acetate, $20 \mathrm{mM}$ citric acid, $3.75 \mathrm{mM}$ sodium octyl sulfate, $1 \mathrm{mM}$ di- $n$-butylamine, $0.134 \mathrm{mM}$ EDTA and 5\% (V/V) methanol. All separations were performed isocratically at a flow-rate of 0.9 $\mathrm{ml} / \mathrm{min}$ at $35^{\circ} \mathrm{C}$. The detector potential was maintained at $+0.65 \mathrm{~V}$.

\section{TH activity analysis}

$\mathrm{TH}$ activity was measured by a modification of the method of Nagatsu et al. (13). The tissues were homogenized with $0.25 \mathrm{M}$ sucrose ( 7 volumes for the abdominal aorta and 15 volumes for the mesenteric artery) in a glass tissue grinder. The standard incubation medium consisted of the following components in a total volume of $250 \mu \mathrm{l}$ : $100 \mu$ l of tissue homogenate, $40 \mu \mathrm{l}$ of $1 \mathrm{M}$ sodium acetate buffer (pH 6.0), $40 \mu$ l of $1 \mathrm{mM}$ L-tyrosine, $20 \mu 1$ of $1 \mathrm{mM}$ 6-methyl-5,6,7,8-tetrahydropterine in $1 \mathrm{M}$ 2-mercaptoethanol, $20 \mu \mathrm{l}$ of $20 \mathrm{mM}$ catalase and $30 \mu \mathrm{l}$ of water. For the blank incubation, D-tyrosine was used as the substrate instead of L-tyrosine. The medium was incubated at $37^{\circ} \mathrm{C}$ for $30 \mathrm{~min}$, and the reaction was terminated by adding to it $200 \mu \mathrm{l}$ of $1 \mathrm{M}$ perchloric acid containing $0.1 \mu \mathrm{g} / \mathrm{ml}$ dihydroxybenzylamine as an internal standard and $50 \mu$ of $0.2 \mathrm{M}$ EDTA, in an ice bath. After $10 \mathrm{~min}$, $150 \mu \mathrm{l}$ of $1 \mathrm{M}$ potassium carbonate and $1 \mathrm{ml}$ of $0.2 \mathrm{M}$ Tris- $\mathrm{HCl}$ ( $\mathrm{pH} \mathrm{8.5)} \mathrm{containing} \mathrm{1 \%} \mathrm{EDTA} \mathrm{were} \mathrm{added,} \mathrm{and}$ the mixture was centrifuged at $1,800 \times g$ for $5 \mathrm{~min}$. To extract DOPA, the supernatant was mixed with $10 \mathrm{mg}$ aluminum oxide and $100 \mu \mathrm{l}$ of $2 \mathrm{M}$ Tris-EDTA ( $\mathrm{pH} 8.7$ ) for 15 $\min$. The precipitate was washed with $1 \mathrm{ml}$ of $16.5 \mathrm{mM}$ Tris-EDTA (pH 8.1), dried and then mixed with $200 \mu$ of solvent medium (acetic acid : 10\% sodium metabisulfite : $5 \%$ EDTA : water $=0.1: 0.05: 0.05: 9.8$ ) for $15 \mathrm{~min}$. This medium was centrifuged at $1,800 \times g$ for $1 \mathrm{~min}$. Forty microliters of supernatant was transferred to a new tube and mixed with $17 \mu \mathrm{l}$ of $0.1 \mathrm{~N} \mathrm{NaOH}$ and $10 \mathrm{mg}$ of Amberlite CG-50 (Aldrich Chem., Co., Milwaukee, WI, USA) for $15 \mathrm{~min}$. The supernatant was passed through a $0.22-\mu \mathrm{m}$ filter, and a $20-\mu 1$ aliquot was into the HPLC (Waters 510) instrument, which was equipped with an electrochemical detector (Waters 460) and a Cosmosil $5 \mathrm{C}_{18}$ AR packed column $(4.6 \times 150 \mathrm{~mm}$, Nacalai Tesque Co.). The mobile phase consisted of the following components: $50 \mathrm{mM}$ sodium acetate, $20 \mathrm{mM}$ citric acid, 12.5 $\mathrm{mM}$ sodium octyl sulfate, $1 \mathrm{mM}$ di- $n$-butylamine and $0.134 \mathrm{mM}$ EDTA. All separations were performed isocratically at a flow-rate of $0.6 \mathrm{ml} / \mathrm{min}$ at $28^{\circ} \mathrm{C}$. The detector potential was maintained at $+0.65 \mathrm{~V}$. TH activity was calculated as the amount of DOPA formed from tyrosine per hour per $\mathrm{g}$ tissue.

\section{Statistical analyses}

Data are presented as the means \pm S.E. Statistical difference between mean values were analyzed by Student's $t$ test; $P$ values less than 0.05 were considered statistically significant.

\section{RESULTS}

The effects of castration and testosterone replacement on systolic blood pressure of SHR and WKY

Figure 1 shows the effects of castration and testosterone replacement on the systolic blood pressure of SHR and WKY. The systolic blood pressure of intact SHR $(195.7 \pm 3.0 \mathrm{mmHg})$ was significantly higher than that of intact WKY $(144.7 \pm 2.3 \mathrm{mmHg})(\mathrm{P}<0.01)$. The systolic blood pressure of castrated SHR $(172.1 \pm 2.6 \mathrm{mmHg})$ was significantly lower than those of intact SHR $(\mathrm{P}<0.01)$ 


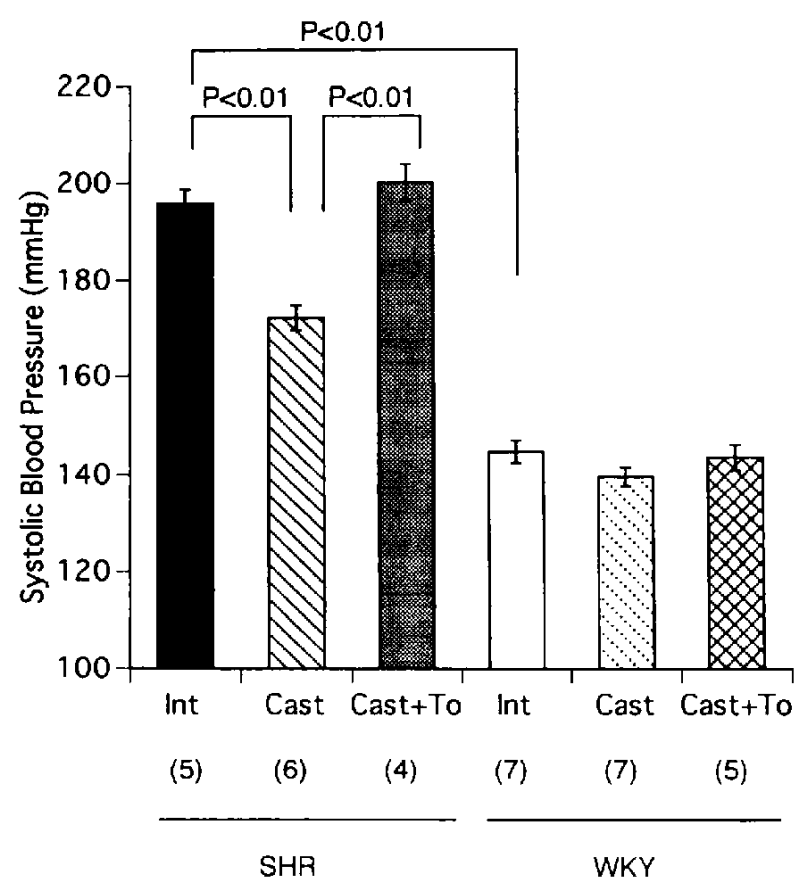

Fig. 1. The effects of castration and testosterone replacement on systolic blood pressure in SHR and WKY. Values are means \pm S.E. Int: intact, Cast: castrated, Cast + To: castrated and testosterone replaced. The number of rats measured is shown in parentheses. The significance of the difference was analyzed by Student's $t$-test. and testosterone-replaced SHR $(200.1 \pm 3.8 \mathrm{mmHg})$ $(\mathrm{P}<0.01)$. The systolic blood pressure of WKY showed no significant differences among the three groups: castrated WKY $(139.6 \pm 1.9 \mathrm{mmHg})$ and testosterone-replaced WKY $(143.4 \pm 2.6 \mathrm{mmHg})$.

The effects of castration and testosterone replacement on the NE levels in the abdominal aorta and mesenteric artery of SHR and WKY

Figure 2 shows the effects of castration and testosterone replacement on the NE levels in the abdominal aorta and mesenteric artery of SHR and WKY. The NE levels of intact SHR (abdominal aorta: $272.0 \pm 14.3 \mathrm{ng} / \mathrm{g}$ tissue, mesenteric artery: $2275.6 \pm 114.8 \mathrm{ng} / \mathrm{g}$ tissue) were significantly higher than those of intact WKY (abdominal aorta: $197.6 \pm 11.5 \mathrm{ng} / \mathrm{g}$ tissue, mesenteric artery: $1294.6 \pm 224.2 \mathrm{ng} / \mathrm{g}$ tissue) $(\mathrm{P}<0.01)$. The $\mathrm{NE}$ levels of castrated SHR (abdominal aorta: $221.8 \pm 10.6 \mathrm{ng} / \mathrm{g}$ tissue, mesenteric artery: $1554.3 \pm 295.1 \mathrm{ng} / \mathrm{g}$ tissue) were significantly lower than those of intact SHR $(P<0.05)$. The NE levels of testosterone-replaced SHR (abdominal aorta: $269.9 \pm 32.9 \mathrm{ng} / \mathrm{g}$ tissue, mesenteric artery: $2238.0 \pm 144.2 \mathrm{ng} / \mathrm{g}$ tissue) recovered to the levels of intact SHR. The NE levels of WKY showed no significant differences among the three groups: castrated WKY (abdominal aorta: $174.5 \pm 12.7 \mathrm{ng} / \mathrm{g}$ tissue, mesenteric artery: $1464.0 \pm 177.3 \mathrm{ng} / \mathrm{g}$ tissue) and testosterone-
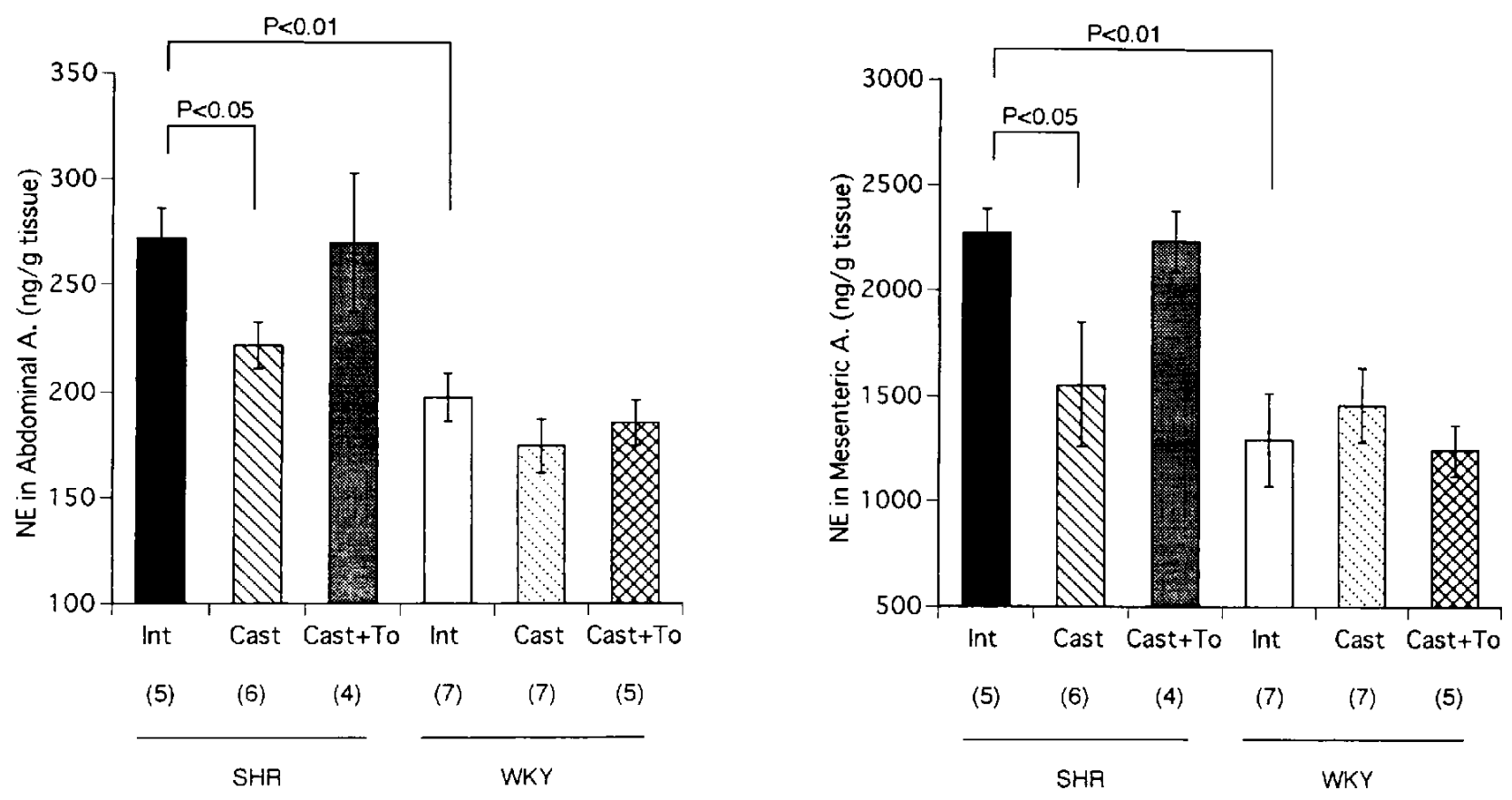

Fig. 2. The effects of castration and testosterone replacement on NE levels in the abdominal aorta and mesenteric artery of $S H R$ and WKY. Values are means \pm S.E. The number of rats measured is shown in parentheses. The significance of the difference was analyzed by Student's $t$-test. See the legend of Fig. 1 for details. 

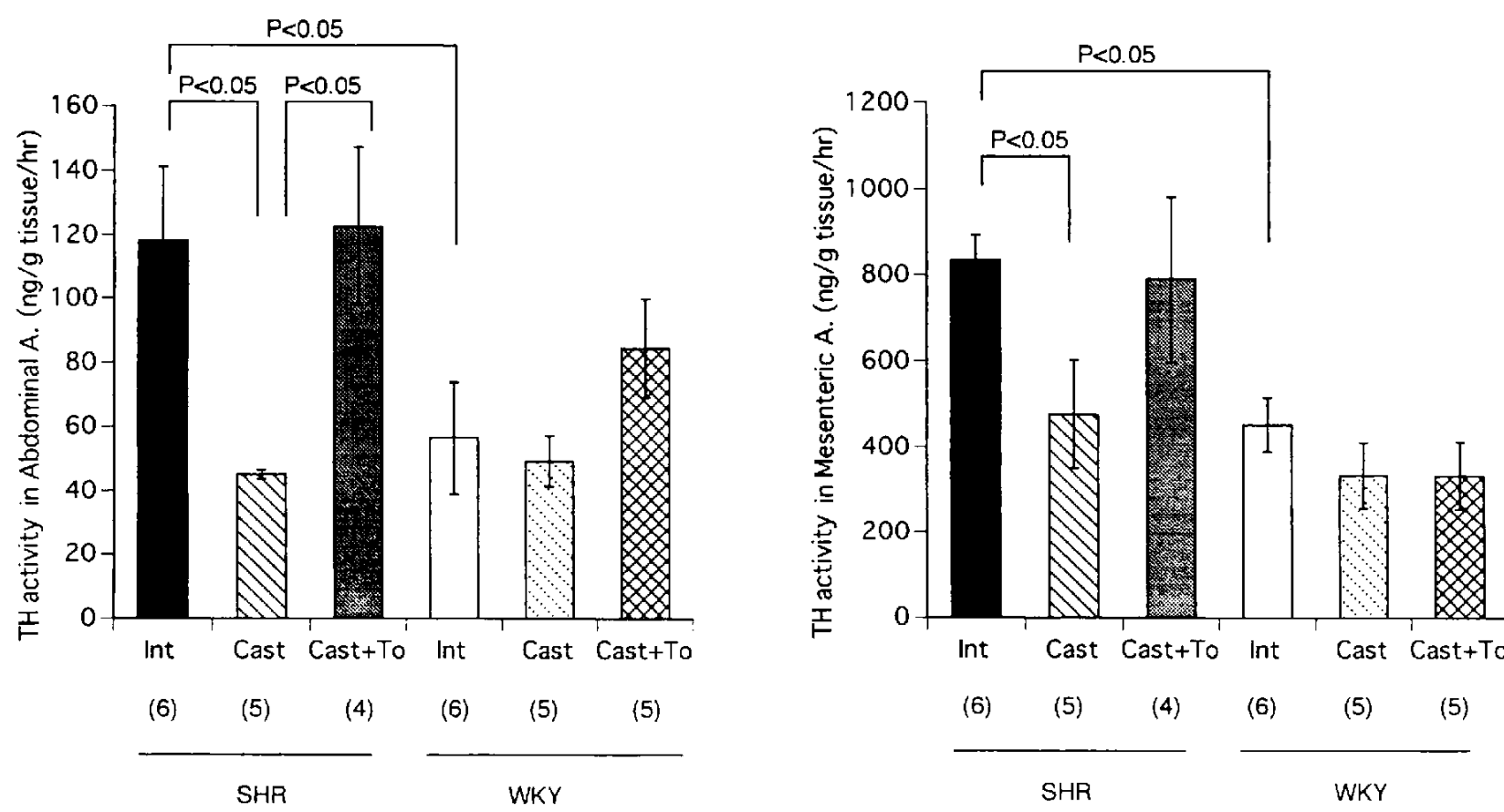

Fig. 3. The effects of castration and testosterone replacement on TH activities in the abdominal aorta and mesenteric artery of SHR and WKY. Values are means \pm S.E. The number of rats measured is shown in parentheses. The significance of the difference was analyzed by Student's $t$-test. See the legend of Fig. 1 for details.

replaced WKY (abdominal aorta: $185.6 \pm 11.0 \mathrm{ng} / \mathrm{g}$ tissue, mesenteric artery: $1247.8 \pm 122.4 \mathrm{ng} / \mathrm{g}$ tissue).

\section{The effects of castration and testosterone replacement on TH activities of the abdominal aorta and mesenteric ar- tery of SHR and WKY}

Figure 3 shows the effects of castration and testosterone replacement on TH activities in the abdominal aorta and mesenteric artery of SHR and WKY. The TH activities of intact SHR (abdominal aorta: $118.2 \pm 23.0 \mathrm{ng} / \mathrm{g}$ tissue/hr, mesenteric artery: $833.0 \pm 60.9 \mathrm{ng} / \mathrm{g}$ tissue/hr) were significantly higher than those of the intact WKY (abdominal aorta: $56.6 \pm 17.4 \mathrm{ng} / \mathrm{g}$ tissue $/ \mathrm{hr}$, mesenteric artery: $450.3 \pm 63.1 \mathrm{ng} / \mathrm{g}$ tissue $/ \mathrm{hr})(\mathrm{P}<0.05)$. The $\mathrm{TH}$ activities of castrated SHR (abdominal aorta: $45.2 \pm 1.4 \mathrm{ng} / \mathrm{g}$ tissue $/ \mathrm{hr}$, mesenteric artery: $474.6 \pm 126.4 \mathrm{ng} / \mathrm{g}$ tissue $/ \mathrm{hr}$ ) were significantly lower than those of intact SHR $(\mathrm{P}<0.05)$. The TH activities of testosterone-replaced SHR (abdominal aorta: $122.8 \pm 24.6 \mathrm{ng} / \mathrm{g}$ tissue $/ \mathrm{hr}$, mesenteric artery: $787.5 \pm 191.8 \mathrm{ng} / \mathrm{g}$ tissue $/ \mathrm{hr}$ ) recovered to the levels of intact SHR. The TH activities of WKY showed no significant differences among the three groups: castrated WKY (abdominal aorta: $49.4 \pm 7.8 \mathrm{ng} / \mathrm{g}$ tissue $/ \mathrm{hr}$, mesenteric artery: $331.8 \pm 77.3 \mathrm{ng} / \mathrm{g}$ tissue $/ \mathrm{hr}$ ) and testosteronereplaced WKY (abdominal aorta: $84.6 \pm 15.4 \mathrm{ng} / \mathrm{g}$ tissue $/ \mathrm{hr}$, mesenteric artery: $331.2 \pm 78.6 \mathrm{ng} / \mathrm{g}$ tissue $/ \mathrm{hr}$ ).

\section{DISCUSSION}

In this study, we observed that the castration of male SHR retarded development of hypertension and that testosterone replacement reversed this retardation. However, neither castration nor testosterone replacement had any effects on the systolic blood pressure of WKY. Iam and Wexler (14) demonstrated that gonadectomy at an early age (30 days) retards the development of hypertension in SHR. We have previously reported that late gonadectomy of SHR (17 weeks) also significantly reduced blood pressure (8). Ganten et al. (11) demonstrated that chemical castration with cyproterone and flutamide, which are androgen receptor antagonists, attenuates the development of hypertension in male SHR. Lengsfeld et al. (15) and Chen and Meng (16) also suggested that androgen is important in producing the male pattern of hypertension in SHR. These findings suggested that androgen may be involved in the SHR's hypertension.

Vascular catecholamines are related to vascular resistance; and in particular, NE is reported to be important in the tonic response to nerve stimulation (17). The NE levels and the TH activities in the abdominal aorta and the mesenteric artery of SHR were significantly higher than those of WKY. Iriuchijima (6) reported that the elevation of the SHR's vascular resistance is not 
uniformly observed over the whole body, and it is especially marked in the abdominal aorta and the mesenteric artery. The vascular resistance of these arteries of SHR was about $50 \%$ greater than that of normotensive rats (18). The present study suggests that the elevated NE level which is likely to result from the high activity of TH in the abdominal aorta and the mesenteric artery may be related to the SHR's increased vascular resistance.

The NE levels in the abdominal aorta and the mesenteric artery were reduced by castration of SHR, while testosterone replacement reversed the decrease in the SHR's NE level. Moreover, the alterations of TH activities by these treatments were consistent with those of the NE level of SHR. On the other hand, neither castration nor testosterone replacement had any effects on the NE level or TH activity in normotensive WKY. Kohler et al. (19) reported that gonadectomy of normotensive male and female Sprague-Dawley strain rats did not alter the TH activities in the mesenteric artery or the vein, and that testosterone had no effect on vascular TH activity. These findings suggest that the effects of testosterone on the NE synthetic pathway were specifically exhibited in the SHR. The underlying mechanisms by which testosterone affects NE level and TH activities of SHR are not yet understood.

There have been inconsistent data on plasma testosterone levels in SHR and WKY. We observed that the plasma testosterone concentration of SHR was significantly higher than that of WKY at the age of 14 weeks (unpublished data). However, Saito et al. (20) reported that the plasma testosterone of SHR was lower than WKY at the age of 8 months. These findings might show that agerelated change of plasma testosterone levels in SHR is different from that in WKY. Further study will be needed to assess plasma androgen level and its influence on NE level and TH activity of SHR.

Changes in NE level and TH activity may result from the direct interaction of androgen with these arteries or sympathetic ganglion containing the TH gene. Notably, the ganglion contains cytosolic androgen receptors that specifically bind to androgen with high affinity in a saturable manner (21). Testosterone is known to play important roles in gene transcription (22). Regulation of specific gene transcription by steroid hormones is mediated by binding of hormone receptors to steroid responsive elements (23). Therefore, it is possible that the changes in $\mathrm{NE}$ level and TH activity by testosterone may be induced via alteration of the TH gene transcription in SHR. Turner et al. (24) have reported that the blood pressure increase shown by male SHR over WKY was related to the Y chromosome. Furthermore, Ganten et al. (11) reported that the blood pressure is higher in male hypertensives than female ones and that this sexual dimorphism is not present in normotensive rats, and they suggested that this sexual dimorphism in SHR is linked to the "hypertensive genes". Therefore, the high blood pressure in male SHR may be related to the action of androgen, which interacts with "hypertensive genes" in the abdominal aorta and mesenteric artery or sympathetic ganglion.

In conclusion, our results suggested that androgen may contribute to the hypertension in male SHR, which increased NE levels due to the high TH activities of the abdominal aorta and the mesenteric artery.

\section{REFERENCES}

1 Yamori Y: Development of the spontaneously hypertensive rat (SHR) and of various spontaneous rat models, and their implications. In Handbook of Hypertension, Edited by de Jong W, Vol 4, Experimental and Genetic Models of Hypertension, pp 224-239, Elsevier Science Publishing Co, Amsterdam (1984)

2 Yamori Y: Pathogenesis of spontaneous hypertension as a model for essential hypertension. Jpn Circ J 41, 259-266 (1977)

3 Dietz R, Schomig A and Rascher W: Pathophysiological aspects of genetically determined hypertension in rats, with special emphasis on stroke-prone spontaneously hypertensive rats. In Handbook of Hypertension, Edited by de Jong W, Vol 4, Experimental and Genetic Models of Hypertension, pp 256-285, Elsevier Science Publishing Co, Amsterdam (1984)

4 Grobecker H, Roizen MF, Weise V, Saavedra JM and Kopin IJ: Sympathoadrenal medullary activity in young spontaneously hypertensive rats. Nature 258, 267 (1975)

5 Judy WV, Watanabe AM, Henry DP, Besch HR, Murphy WR and Hockel GM: Sympathetic nerve activity. Role in regulation of blood pressure in the spontaneously hypertensive rat. Circ Res 38, II-21-II-29 (1976)

6 Iriuchijima J: Regional blood flow in conscious spontaneously hypertensive rats. Jpn J Physiol 33, 41-50 (1983)

7 Hypertension detection and follow-up cooperative group: Race, education and prevalence of hypertension. Am J Epidemiol 106, $351-361$ (1977)

8 Masubuchi Y, Kumai T, Uematsu A, Komoriyama K and Hirai $\mathrm{M}$ : Gonadectomy-induced reduction of blood pressure in adult spontaneously hypertensive rats. Acta Endocrinol 101, $154-160$ (1982)

9 Hirai M, Masubuchi Y, Kumai T and Ohno T: Inhibition of the pathogenesis of spontaneous hypertension in SHR by gonadectomy: difference from adrenal regeneration hypertension. Ipn Heart J 25, 839-841 (1984)

10 Cambotti LJ, Cole FE, Gerall AA, Frohlich ED and MacPhee AA: Neonatal gonadal hormones and blood pressure in the spontaneously hypertensive rat. Am J Physiol 247, 258-264 (1984)

11 Ganten U, Schroder G, Witt M, Zimmermann F, Ganten D and Stock G: Sexual dimorphism of blood pressure in spontaneously hypertensive rats: effects of anti-androgen treatment. J Hypertens 7, 721-726 (1989)

12 Hamill RW and Schroeder BM: Hormonal regulation of adult sympathetic neurons: the effects of castration on neuropeptide $\mathrm{Y}$, norepinephrine and tyrosine hydroxylase activity. J Neurobiol 21, 731-742 (1990)

13 Nagatsu T, Oka K and Kato T: Highly sensitive assay for tyro- 
sine hydroxylase activity by high-performance liquid chromatography. J Chromatogr 163, 247-252 (1979)

14 Iam SG and Wexler BC: Retardation in the development of spontaneous hypertension in SH rats by gonadectomy. J Lab Clin Med 90, 997-1007 (1977)

15 Lengsfeld M, Morano I, Ganten U, Ganten D and Ruegg JC: Gonadectomy and hormonal replacement changes systolic blood pressure and ventricular myosin isozyme pattern of spontaneously hypertensive rats. Circ Res 63, 1090-1094 (1988)

16 Chen Y-F and Meng Q-C: Sexual dimorphism of blood pressure in spontaneously hypertensive rats is androgen dependent. Life Sci 48, 85-96 (1991)

17 Sjoblom-Widfeldt $\mathrm{N}$ and Nilsson $\mathrm{H}$ : Sympathetic transmission in small mesenteric arteries. Phasic and tonic components. In Resistance Arteries, Edited by Mulvany MJ, Aalkjaer C, Heagerty AM, Nyborg NCB and Strandgaard S, pp 160-163, Excerpta Medica, Amsterdam (1991)

18 Iriuchijima J: Mechanism of elevation of hindquarter vascular resistance in spontaneously hypertensive rats. Jpn J Physiol 35, $45-56$ (1985)

19 Kohler C, Berkowitz BA and Spector S: Sex hormones and tyro- sine hydroxylase activity in vascular and adrenal tissue. Endocrinology 97, 1316-1320 (1975)

20 Saito N, Mitsuuchi Y, Konishi Y and Nishiyama S: The change of plasma testosterone by aging in male stroke-resistant SHR. Jpn Heart J 33, 563 (1992)

21 Melvin JE, McNeill TH, Hervonen A and Hamill RW: Organizational role of testosterone on the biochemical and morphological development of the hypogastric ganglion. Brain Res 485, 1 - 10 (1989)

22 Goldstein ME, Tank AW, Fossom LH and Hamill RW: Molecular aspects of the regulation of tyrosine hydroxylase by testosterone. Mol Brain Res 14, 79-86 (1992)

23 Tsai MJ and O'Malley BW: Mechanisms of regulation of gene transcription by steroid receptors. In The Hormonal Control Regulation of Gene Transcription, Edited by Cohen $\mathrm{P}$ and Foulkes JG, pp 101-116, Elsevier Science Publishing Co, Amsterdam (1991)

24 Turner ME, Johnson ML and Ely DL: Separate sex-influenced and genetic components in spontaneously hypertensive rat. Hypertension 17, 1097-1103 (1991) 